1 Piracicaba Dental School, University of Campinas, Piracicaba, São Paulo, Brazil

${ }^{2}$ State University of Ponta Grossa, Ponta Grossa, Paraná, Brazil

${ }^{3}$ Department of Dentistry at State University of Ponta Grossa, Paraná, Brazil
Corresponding author: Marcos Pomini

Department of Prosthodontics and Periodontics, Piracicaba Dental School, University of Campinas Avenida Limeira, 901, Areião, Piracicaba-SP, Brazil

Email: marcospomini@outlook.com Tel: +55(45)988123993

Received: April 23, 2019

Accepted: July 17, 2019

\section{In vitro fracture strength and modes of cast post and cores luted with self-adhesive resin-based cement}

Marcos C Pomini ${ }^{1, *}$, Marina M Machado ${ }^{2}$, Giovanny de Paula Quadros ${ }^{2}$, Lidia O B Pinheiro, ${ }^{3}$ Adriana P B Samra ${ }^{3}$

Cast post and core (CPC) remains one of the most used post type; however, the biomechanical behavior of CPCs luted with self-adhesive (SA) resin-based cement is unclear. Aim: To evaluate the fracture resistance (FR) and fracture modes of teeth restored with CPCs luted with zinc-phosphate (ZP) or resin-based SA cements, as well as the infuence of the coronal remnant. Methods: Twenty-four recently extracted human premolars were divided into four groups according to the cement used (ZP or SA) and residual tooth structure (with or without $2 \mathrm{~mm}$ ). We then tested FR using a universal machine and analyzed data using two-way ANOVA and Tukey HSD ( $a=.05)$. Fracture modes were classifed according to the degree of dental destruction Results: No difference was found in FR $(p=.352)$; however, teeth without ferrules presented more irreparable fractures, especially in the ZP group. Conclusion: Luting CPCs with SA resin-based cement does not enhance FR, but it reduces the number of irreparable fractures compared to ZP cement.

Keywords: Post and core technique. Resin cements. Adhesiveness. Fractures, compression. 


\section{Introduction}

Post restoration choice and ferrule affect the prognosis of endodontically treated teeth $^{1,2}$. Although the use of fiber reinforced composite posts is increasing in contemporary dentistry ${ }^{2}$, cast post and cores (CPCs) remain one of the most used post type ${ }^{3,4}$. Metal-based CPCs exhibit great long-term clinical results and are still used successfully 5,6 because they present a better fit for root canal irregularities, avoid excessive canal preparation, and are preferred in situations involving insufficient ferrules or for supporting fixed partial dentures ${ }^{7}$.

Luting agents are expected to increase the retention of the post and core restoration and maintain its integrity 5 . On the other hand, zinc-phosphate cements (ZP) have poor mechanical and biological properties, lower compressive strength, and high solubility ${ }^{8}$. Self-adhesive (SA) resin-based cements were introduced with an organic multifunctional methacrylate matrix, which not only conditions the tooth surface, but also contributes to adhesion ${ }^{5}$. The adhesive cementation of posts and cores is of great significance to the stability and strength of the overall rehabilitation ${ }^{5}$, however, the mechanical behavior of SA adhesion to metal-based CPCs remains unclear in the literature. Thus, in this in vitro study, we aimed to evaluate the fracture resistance (FR) and fracture modes of teeth with and without ferrules restored with CPCs luted with ZP or SA resin-based cement. We tested the following hypothesis: self-adhesion enhances $\mathrm{FR}$ and reduces irreparable fractures in endodontic treated teeth restored with CPCs.

\section{Materials and Methods}

The ethics committee of the State University of Ponta Grossa approved this study's experimental protocol. The sample consisted of twenty-four recently extracted human single-rooted premolars. Half of the teeth $(n=12)$ were decoronated at the cementenamel junction, and the other half decoronated $2 \mathrm{~mm}$ coronally. The roots received standard endodontic treatments and post space preparations. Resin patterns were cast in copper-aluminum alloy 9 . Prior to cementation, the roots were irrigated with $2.5 \%$ sodium hypochlorite, rinsed with distilled water, and dried gently with blown air, followed by absorbed points. Twelve specimens were cemented with ZP cement (LS, Coltene, Rio de Janeiro, Brazil), and the other 12 were cemented with a SA resin-based cement (RelyX U200, 3M ESPE, St. Paul, MN, USA). The roots were divided into four groups $(n=6)$ according to coronal remnant (with or without $2 \mathrm{~mm}$ ) and cementing agent (ZP or SA).

Twenty-four hours and five minutes after cementation, the SA and ZP roots were prepared for metal-free crowns, respectively, and received self-curing acrylic resin (Vipiflash; VIPI, Pirassununga, Brazil) crowns made using preformed acetate matrices (TDV Dental, Pomerode, Brazil). The crowns were luted with RelyX U200. To provide a more accurate assessment of human root fracture strength, the alveolar bone and periodontal ligament were simulated by dipping the root surfaces into melted wax (Asfer, São Caetano do Sul, Brazil) up to $2 \mathrm{~mm}$ below the CEJ, resulting in a wax layer approximately $0.3 \mathrm{~mm}$ thick. The roots were then placed in polyvinyl chloride tubes filled with self-curing acrylic resin (VIPI). After 24 hours, the wax was removed 
and replaced with polyether impression material (3M ESPE, St. Paul, MN, USA). One week after cementation, the samples were submitted to a compressive load (AG-I; Shimadzu, Columbia, USA) at a crosshead speed of $0.5 \mathrm{~mm} / \mathrm{min}$ and angulation of $150^{\circ}$ until fracture ${ }^{10}$. The values were submitted to two-way ANOVA, followed by Tukey HSD $(a=.05)$, and the fracture modes were classified based on the degree of dental destruction: reparable (crown displacement or fracture, or horizontal fracture in the cervical third) or irreparable (vertical or oblique root fracture, or horizontal fracture in the apical or middle third), which would require tooth extraction.

\section{Results}

We found no significant difference in FR among the groups ( $p=.352)$ regardless of ferrule presence (Table 1). However, Table 2 shows that teeth with ferrules presented one irreparable fracture (8.3\%), whereas teeth without ferrules presented three (25\%). In the absence of ferrules, the ZP group presented 3 irreparable fractures (50\%), whereas the SA group presented 1 (16.7\%).

\section{Discussion}

Our results show that the chemical adhesion of CPCs does not enhance FR, but it reduces the number of irreparable fractures, especially in the presence of $2 \mathrm{~mm}$ coronal remnant. Similarly, in a clinical setting, Behr et al. ${ }^{8}$ found no difference when luting metal-based materials with ZP and SA. Because CPC retention with ZP depends on friction along the root canal, it transmits the stress directly to the dentinal walls, increasing root fractures ${ }^{3}$. In addition, the adhesion of posts to the root canal has been described as reducing stress transmission to the root because it promotes

Table 1. Mean and standard deviation $(N)$ of the failure loads $(n=6)$.

\begin{tabular}{lcc}
\hline \multirow{2}{*}{ Coronal remnant } & \multicolumn{2}{c}{ Cementing agent } \\
\cline { 2 - 3 } & Zinc-phosphate & Resin-based self-adhesive \\
\hline Ferrule present & $1141.2 \pm 149.6^{\mathrm{a}}$ & $1058.4 \pm 188.3^{\mathrm{a}}$ \\
\hline Ferrule absent & $1102.3 \pm 154.4^{\mathrm{a}}$ & $967 \pm 117.1^{\mathrm{a}}$ \\
\hline
\end{tabular}

*Similar letters indicate statistically similar values

Table 2. Fracture modes and overall percentage of repairable and irreparable for the experimental groups $(n=6)$

\begin{tabular}{lccc}
\hline \multirow{2}{*}{ Groups } & \multicolumn{2}{c}{ Repairable } & \multicolumn{2}{c}{ Irreparable } \\
\cline { 2 - 4 } & $\begin{array}{c}\text { Displacement or fracture } \\
\text { of the crown }\end{array}$ & $\begin{array}{c}\text { Vertical or oblique root } \\
\text { fracture }\end{array}$ & $\begin{array}{c}\text { Horizontal root fracture in } \\
\text { the apical or middle third }\end{array}$ \\
\hline ZP/Ferrule (\%) & $5(83.3)$ & - & $1(16.7)$ \\
\hline ZP/without ferrule (\%) & $3(50)$ & $2(33.3)$ & $1(16.7)$ \\
\hline SA/ferrule (\%) & $6(100)$ & - & - \\
\hline SA/without ferrule (\%) & $5(83.3)$ & - & $1(16.7)$ \\
\hline Total (\%) & $79.2 \%$ & $8.3 \%$ & $12.5 \%$ \\
\hline Overall (\%) & $79.2 \%$ & & $20.8 \%$ \\
\hline
\end{tabular}

*ZP: zinc-phosphate cement; SA: resin-based self-adhesive resin cement. 
increased retention and attenuates tooth weakening ${ }^{11}$, reducing the number of irreparable fractures. This corroborates our results. In addition, the most common cause of failure in CPCs luted with ZP cement is retention loss ${ }^{12}$. The strong physical interaction between the methacrylates in SA resin-based cement ${ }^{5}$ may favor adhesion, creating a monoblock restoration. This seems to increase over time ${ }^{13}$ and may favor stress distribution. In a similar setting, Pomini et al. ${ }^{13}$ demonstrated that the bond strength of CPC luted with SA increased after 6 months of storage, indicating that the biomechanical behavior of CPC luted with SA resin-based cement may improve over time, unlike ZP, which is known for lower compressive strength and high solubility in the oral environment. ${ }^{8}$

In addition, the amount of coronal remnant may have influenced the number of root fractures because the remnant modifies the root stress distribution pattern. Teeth with ferrules present higher resistance to functional forces, wedging effects, lateral forces, and greater strength ${ }^{1}$, which may reduce the number of fractures. Ferrule presence is considered the most important factor affecting FR and post and core rehabilitation survival rates ${ }^{2,4,13}$. Nonetheless, metal-based posts and cores have demonstrated the lowest complication rates, being root fractures the most commonly reported complication ${ }^{4}$. Juloski et al. ${ }^{2}$ demonstrated that teeth restored with CPCs are more resistant to fractures than prefabricated posts not only in the absence of ferrules, but also in their presence. On the other hand, in the presence of ferrules, CPCs present similar FR compared to ceramic custom-fabricated posts ${ }^{2}$. Therefore, the better outcomes found for CPCs in the absence of residual tooth structure maybe be the main factor that influences dentists to continue using CPCs instead of newer post types.

However, our results should be evaluated carefully because not all clinical aspects can be reproduced in a laboratory setting. This study evaluated only an oblique incident force, but in the oral cavity, force direction varies. In addition, we used acrylic resin crowns for this study. However, these crowns are routinely used in temporary rehabilitation, often for considerable lengths of time. Because we aimed at evaluating the posts' FR, the use of crowns that do not influence resistance and only superficially dampen compressive forces during the test was considered. Therefore, researchers should conduct additional multi-variable studies to evaluate the long-term performance of SA resin-based luted CPCs.

\section{Conclusion}

The use of SA resin-based cement in CPCs does not promote enhanced FR, but it reduces the number of irreparable fractures considerably, especially in the presence of $2 \mathrm{~mm}$ coronal remnant. Thus, luting CPCs with SA resin-based cement seems to be the ideal choice for endodontically treated teeth.

\section{Acknowledgements}

The authors are grateful to 3M ESPE and TDV, for the donation of the materials employed in this study and to the PhD Professor Giovana Mongruel Gomes for reviewing the final article. 


\section{References}

1. Shamseddine L, Chabaan F. Impact of a Core Ferrule Design on Fracture Resistance of Teeth Restored with Cast Post and Core. Adv Med. 2016;2016: 5073459. doi:10.1155/2016/5073459.

2. Juloski J, Radovic I, Goracci C, Vulicevic ZR, Ferrari M. Ferrule effect: a literature review. J Endod. 2012;38(1):11-9. doi: 10.1016/j.joen.2011.09.024.

3. Soares CJ, Valdivia ADCM, Silva GR, Santana FR, Menezes MS. Longitudinal clinical evaluation of post systems: a literature review. Braz Dent J. 2012;23(2):135-740. doi:10.1590/S0103-64402012000200008.

4. Said YH, Sahib D. "The Use of Post and Core in Public and Private Swedish Dental Care : A Questionnaire Study.” (2018). Available at: http://urn.kb.se/resolve?urn=urn:nbn:se:umu:diva-143912

5. Capa N, Ozkurt Z, Canpolat C, Kazazoglu E. Shear bond strength of luting agents to fixed prosthodontic restorative core materials. Aust Dent J. 2009 Dec;54(4):334-40.

6. Sarkis-Onofre R, Jacinto RC, Boscato N, Cenci MS, Pereira-Cenci T. Cast metal vs. glass fibre posts: A randomized controlled trial with up to 3 years of follow up. J Dent. 2014;42:582-7.

7. Hendi AR, Moharrami M, Siadat H, Hajmiragha H, Alikhasi M. The effect of conventional, half-digital, and full-digital fabrication techniques on the retention and apical gap of post and core restorations. J Prosthet Dent. 2019;121(2):364.e1-364.e6. doi:10.1016/j.prosdent.2018.09.014.

8. Behr M, Rosentritt M, Wimmer J, Lang R, Kolbeck C, Bürgers R, Handel G. Self-adhesive resin cement versus zinc phosphate luting material: a prospective clinical trial begun 2003. Dent Mater. 2009;25(5):601-4. doi:10.1016/j.dental.2008.11.003.

9. Pinto CL, Bhering CLB, de Oliveira GR, Maroli A, Reginato VF, Caldas RA, et al. The Influence of Post System Design and Material on the Biomechanical Behavior of Teeth with Little Remaining Coronal Structure. J Prosthodont. 2019;28(1):e350-e356. doi: 10.1111/jopr.12804.

10. Gomes GM, Gomes OM, Gomes JC, Loguercio AD, Calixto AL, Reis A. Evaluation of different restorative techniques for filling flared root canals: fracture resistance and bond strength after mechanical fatigue. J Adhes Dent. 2014;16(3):267-76. doi:10.3290/j.jad.a31940.

11. Balkaya MC, Birdal IS. Effect of resin-based materials on fracture resistance of endodontically treated thin-walled teeth. J Prosthet Dent. 2013;109(5):296-303.

12. Balkenhol M, Wöstmann B, Rein C, Ferger P. Survival time of cast post and cores: a 10-year retrospective study. J Dent. 2007;35(1):50-8.

13. Carvalho MA, Lazari PC, Gresnigt M, Del Bel Cury AA, Magne P. Current options concerning the endodontically-treated teeth restoration with the adhesive approach. Braz Oral Res. 2018;32(suppl 1):e74. doi:10.1590/1807-3107bor-2018.vol32.0074.

14. Pomini MC, Machado MM, de Paula Quadros G, Gomes GM, Pinheiro LOB, Samra APB. In Vitro Fracture Resistance and Bond Strength of Self-Adhesively Luted Cast Metal and Fiber-Reinforced Composite Posts and Cores: Influence of Ferrule and Storage Time. Int J Prosthodont. 2019;32(2):205-7. doi:10.11607/ijp.5956. 